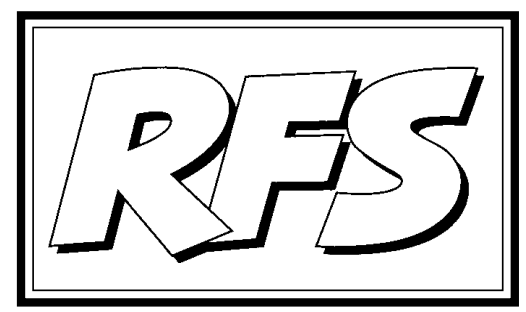

Revista de Fomento Social, 57 (2002), 25-42

\title{
Los orígenes de la protección por maternidad
}

Pilar NÚÑEZ-CORTÉS CONTRERAS

\section{El trabajo asalariado de la mujer en el marco de la Revolución Industrial}

Del complejísimo fenómeno de la industrialización interesan, sobre todo al objeto de nuestro estudio, los problemas sociales de todos los órdenes que arrancaron con el nuevo modelo de sociedad creado por la Revolución Industrial, y en particular, los relativos a la situación de la mujer trabajadora. El trabajo asalariado de la mujer se encuadró en el modelo de relaciones laborales surgido de la Revolución Industrial con la agravante de que la percepción de la trabajadora por la sociedad de la época perjudicó aún más su situación en el mercado de trabajo. Sus condiciones laborales corrieron paralelas a las penosas condiciones de los trabajadores masculinos, en la mayoría de los casos jornadas de diez o doce horas, a lo que se añadió la escasa valoración social del trabajo femenino y por tanto su menor remuneración ${ }^{1}$.

1 P. Folguera Crespo (1997,b), pág. 446. 
Existió a finales del siglo XIX un fuerte rechazo social del trabajo femenino; una buena parte de la sociedad opinaba que el sitio de la mujer estaba en el hogar. El jornal de la mujer fue considerado más una ayuda que un medio de vida familiar, a pesar de que con frecuencia fue el único sostén de la familia pobre. La mayoría de las trabajadoras fueron obreras viudas, esposas abandonadas con hijos, solteras con padres enfermos y viejos, etc... ${ }^{2}$. A medida que avanzó el siglo XX la sociedad comenzó a tolerar el trabajo de las mujeres sólo en situaciones de absoluta necesidad ${ }^{3}$. Reproducimos literalmente, por su enorme carga ideológica, y por ser particularmente expresivo del sentir social, un breve pasaje de un texto de J oan Gaya, un autor catalán de principios del siglo XX: “...habiendo tantos hombres en paro, ¿por qué han de trabajar las mujeres? iAh, por si acaso, por si se quedan solteras! Retened a las jóvenes en casa; dejad que los hombres trabajando puedan constituir una familia y no tengáis miedo de que se queden solteras. Si por el contrario ocupan las plazas de ellos, habréis subvertido el orden social, y entonces sí que se quedarán solteras..." 4 .

También los obreros de finales del XIX y principios del XX participaron de este sentir general; la mujer era una competidora dispuesta siempre a trabajar por un salario bajo, especialmente en situaciones de paro forzoso ${ }^{5}$.

En este contexto socioeconómico el patrono manipuló en su provecho la necesidad de trabajar de un buen numero de mujeres de clase social baja, pagándoles salarios de miseria e imponiéndoles condiciones laborales muy penosas en todos los órdenes, jornadas abusivas, falta absoluta de seguridad, salubridad, higiene, etc... Situación que se configuró como una importantesecuela de la industrialización y un problema social degran trascendencia, que preocupó a muchos sectores de la sociedad de la época y que engrosó a todos los efectos la llamada "cuestión social"6.

Las condiciones de trabajo en algunas fábricas eran durísimas; especialmente en fábricas de paños y mantas de lana se emplearon mujeres en la operación de perchado que exigía no sólo una gran fuerza muscular sino

2 Mạ. C. Iglesias y A. Elorza (1969), pág. 314 y ss.

3 Vid. en extenso de C. De Zulueta (1992), pág. 117 y ss.

4 Recogida la cita por M. NASH (1983), pág. 46.

5 Vid. en extenso, M. NASH (1983), pág. 45 y ss.

6 Por todos M. Tuñón de LARA (1972), pág. 35 y ss. 
permanecer de pie toda la jornada. La duración de ésta era arbitraria y abusiva, existían fábricas que fijaban jornadas superiores a catorce y quince horas sin hacer distinción entre las edades de las obreras ${ }^{7}$.

En cuanto a la explotación salarial, a pesar de la relativa fiabilidad de los datos que aportaremos, resultan ilustrativos y dan una idea aproximada de ella. A lo largo del siglo XIX la mayoría de las mujeres trabajaban en la agricultura cobrando jornales mucho más bajos que los de los hombres, de la mitad a dos tercios más bajos. En el sector industrial, las mujeres prestaban servicios principalmente en la industria textil, donde sus salarios eran sensiblemente inferiores a los de los hombres, la mitad del valor de éstos en la década de 1850 y entre el cuarenta y el sesenta y seis por ciento en la de $1870^{8}$.

Numerosas voces denunciaron desde el punto de vista de la salud pública las nefastas consecuencias del trabajo femenino sobre la maternidad, un buen número de higienistas de la época se hicieron eco de ello en sus trabajos científicos. Demostraron que el peso medio y el volumen de los hijos de las trabajadoras que pasaban el período del embarazo en reposo fueron superiores en 300 gramos $^{9}$. OPISSO puso de relieve la "influencia desastrosa del trabajo femenino en el aborto, el parto prematuro y la mortinatalidad. Esta última alcanza en Barcelona, la ciudad más industrializada, donde hay tantas mujeres ocupadas en trabajos rudos, proporciones considerables. Lo mismo ocurre con los abortos, que habiendo ascendido a 770 en 1898, han ido en aumento cada año hasta llegar a 1.087 en el año 1902"10.

La regulación aplicable en esta época a la prestación de servicios de la trabajadora fue la contenida en el Código Civil de 1889 para el arrendamiento de servicios. Nuestra legislación civil se limitaba a trazar algunas normas generales para este tipo de contratos en los artículos 1583 a 1587, confiando su régimen jurídico más específico a la voluntad de las partes. No existirían en estos preceptos normas restrictivas de la voluntad para favorecer al trabajador salvo la prohibición de contratar servicios perpetuos ${ }^{11}$.

\footnotetext{
7 A. Schubert (1991), págs. 59 y 60.

8 A. SCHubert (1991), págs. 59 y 60.

9 Vid. en extenso, S. Aznar Embid (1932), pág. 14.; M. Martínez Ródenas (1912), pág. 47.

10 A. OpISso (s.f.), pág. 27.

11 Vid. C. Garcia Oviedo (1934), pág. 119.
} 
En el contexto del arrendamiento de servicios y de las relaciones de producción capitalistas, la maternidad de la trabajadora supondría la casi segura pérdida de su puesto de trabajo. En un plano material la maternidad se configuró en esta época como una causa de extinción del contrato de trabajo.

Con seguridad el aumento de tamaño de las empresas en el último decenio del siglo XIX y principios del XX no favoreció una solución consensuada para estas situaciones. Al producirse el tránsito de millares de pequeñas empresas a la gran empresa, la trabajadora quedaría aislada en el nuevo contexto, dificultándose la negociación individual de sus condiciones de trabajo ${ }^{12}$. García Oviedo señala al respecto "aislados no pueden los obreros discutir en buenas condiciones con los patronos el régimen de trabajo. Acuciados por la escasez se ven obligados a pactar con la empresa como ésta quiera"13.

\section{El entorno político de la aparición de la Ley de 13 de marzo de 1900: la influencia del reformismo, el catolicismo social y la presión del movimien- to obrero}

Con carácter tardío en comparación con otros países de nuestro entorno (Inglaterra, Francia...), el 13 de marzo de 1900 se promulgó en España la primera norma que reguló el trabajo de la mujer donde se contemplaba la protección por maternidad de la trabajadora. Las principales causas de su retraso posiblemente fueron la agitación propia de la política nacional del siglo XIX y la tardía implantación de la Revolución Industrial en España con la correspondiente inhibición de la polémica intervencionista en nuestro país.

El reformismo liberal moderado de la Restauración favoreció a partir de 1876 la hegemonía de la llamada "cultura liberal", propiciando un clima de tolerancia que facilitó el desarrollo ordenado y normalizado de la política en nuestro país. Cánovas logró crear un sistema bipartidista, un turno regular entre el partido conservador y liberal, que definió la política de 1876 a 191314. Esta estabilidad hizo posible la toma de conciencia por parte del Estado de la necesidad de abordar reformas, sobre to do en las cuestiones sociales de

\footnotetext{
12 M. Tuñón de LaRA (1972), pág. 379 a 381.

13 Vid. C. García Oviedo (1934), pág. 12 y ss.

14 J. P. Fusi, y J. Palafox (1997).
} 
carácter urgente como la protección del trabajo de las mujeres y niños. La asunción por parte del Estado de la necesidad de legislar sobre ello no supuso una ruptura de dogmas e ideas fundamentales para el "orden liberal", en concreto la protección de la maternidad de la mujer trabajadora fue abordada como una cuestión de salud y orden público ${ }^{15}$.

Siendo Ministro de la Gobernación Segismundo Moret, fue creada la Comisión de Reformas Sociales por Real Decreto de 5 de diciembre de $1883^{16}$. En sus comienzos la principal labor de la Comisión fue la recogida, posterior ordenación y publicación de la información oral y escrita sobre las necesidades de las clases obreras, documentación que fue básica para ilustrar posteriormente el proceso legislativo. Un poco más adelante su objetivo se desdobló en dos, por un lado, con carácter de urgencia, plasmar en leyes algunas de las reivindicaciones sociales como la regulación del trabajo femenino, y por otro lado estimular la participación de las fuerzas sociales y el Gobierno en torno a la resolución de estos problemas ${ }^{17}$. Con esta finalidad, la Comisión fomentó la participación en sus tareas de un buen número de asociaciones obreras, organizaciones sociales de todo tipo y expertos interesados en la "cuestión social". A pesar de todo, hubo un rechazo generalizado y un fuerte escepticismo de la clase obrera, particularmente entre los anarquistas, hacia su labor por tratarse de una iniciativa gubernamental ${ }^{18}$.

Hasta 1890, la Comisión de Reformas Sociales permaneció reducida a un núcleo de personalidades de la ciencia y la política partidarias de la reforma social que promovieron la publicación de la información oral como base de partida de toda su labor y que lucharon por ser oídos en los escasos proyectos legislativos que en materia social se elaboraron en esta época. A partir de 1890, la Comisión de Reformas Sociales sufrió una reorganización, desde entonces promovió diversas iniciativas legislativas y en concreto algunas relacionadas con la protección por maternidad. Los reformistas se enfrentaron con actitud paternalista a los problemas relativos al trabajo de la mujer, prestando una atención casi exclusiva a las cuestiones perjudiciales para la trabajadora como madre. Por sus planteamientos esencialmente

15 J. I. Palacio Morena (1988), pág. 156.

16 L. E. De la Villa GiL (1970), pág. 7.

17 J. I. Palacio Morena, pág. 141.

18 Ministerio de Trabajo y Seguridad Social (1985), Reformas Sociales, Información Oral en Madrid, tomo I, 1889, Madrid, pág. 24. 
tutelares el trabajo femenino fue para ellos un campo privilegiado de acción social ${ }^{19}$.

En la última década del siglo XIX, a partir de la recepción madura en nuestro país de la Encíclica Rerum Novarum en 1894-95, aumentó el interés de los medios católicos por la legislación social. En 1895 se creó la Asociación General madrileña como respuesta de los católicos a la invitación de León XIII a la acción social, entre sus objetivos estuvieron el estudio y preparación de proyectos legislativos sociales. Para el "catolicismo social" el trabajo de la mujer fue una cuestión de importancia extrema, su óptica al igual que la de los reformistas fue esencialmente la de la defensa de la familia tradicional y el papel de la trabajadora madre 20 .

La coincidencia básica de planteamientos ideológicos entre reformistas y católicos propició su estrecha colaboración en la redacción de la primera legislación social; algunas personalidades vinculadas al catolicismo social participaron también en los trabajos de la Comisión de Reformas Sociales. En el año 1899 "la Asociación General" desarrolló una intensa actividad legislativa, elaboró hasta once proyectos legislativos, una parte de los cuales abordaba cuestiones específicamente laborales, y entre ellas el trabajo de la mujer. La participación activa y directa de los católicos que presionaron desde la "Asociación General" tuvo al parecer una influencia decisiva sobre la presentación y aprobación de los proyectos sociales de Eduardo Dato21.

Este sosiego político de la última década del siglo XIX propició varias tentativas legislativas que no llegaron a cuajar. En la legislatura de 1891 el Senado conoció un proyecto de ley sobre el trabajo de la mujer, en la de 1893-94 el ministro de la Gobernación Alberto Aguilera presentó al Congreso uno nuevo regularizando el trabajo de la mujer en los establecimientos industriales (8-6-1894); pocos años más tarde en el período de 1898-99 el Congreso de los Diputados estudió nuevamente otro promovido por el ministro de la Gobernación Ruiz de Capdeón sobre la "reglamentación del trabajo de la mujer". Finalmente el proyecto, fuertemente criticado en los medios obreros, que Eduardo Dato había remitido al Senado en 1889 se convirtió en la Ley de 13 de marzo de 1900. La contestación obrera fue

\footnotetext{
19 J.I. Palacio Morena (1988), pág. 156.

20 Vid. en extenso, F. Montero García (1983), pág. 405.

21 Vid. en extenso, F. Montero García (1983).
} 
posiblemente la razón fundamental para que se demorase tanto su conversión en ley. Asimismo el crecimiento de la conflictividad social a finales del siglo XIX, protagonizada por un movimiento obrero en franco desarrollo, engrasó la maquinaria legislativa para la aparición de la primera legislación protectora del trabajo de la mujer ${ }^{22}$.

\section{La normativa sobre protección por maternidad de la trabajadora de las primeras décadas del siglo $\mathrm{XX}$}

La Ley de 13 de marzo de $1900^{23}$, así como su posterior redacción de 8 de enero de $1907^{24}$, otorgaba a la mujer encinta el derecho a descansar en la última parte del embarazo, a la vez que le imponía la obligación de no trabajar durante varias semanas después del alumbramiento con pérdida de su remuneración y reserva de su puesto de trabajo en ambos casos.

A pesar de que el legislador burgués sostuvo la intención de que esta norma se acatase para garantizar la continuidad del sistema en su propio beneficio, sin embargo resultó escasamente aplicada. La situación de absoluta necesidad de las trabajadoras no les permitió ejercitar los derechos que la norma les reconoció; además los mecanismos coercitivos de la norma frente a los incumplimientos del empresario fueron débiles y tampoco existió una mínima infraestructura administrativa para poder exigir su cumplimiento. No obstante, sirvió de punto de partida y de molde, que se fue perfeccionado a lo largo de las sucesivas etapas legislativas; con el paso del tiempo, al

22 M. NASH (1983), pág. 57.

23 Art. noveno de la Ley de 13 de marzo de 1900: “No se permitirá el trabajo a las mujeres durante las tres semanas posteriores al alumbramiento. Cuando se solicite por causa del próximo alumbramiento por una obrera el cese se le reservará el puesto desde que lo haya solicitado y tres semanas después de dicho alumbramiento".

24 Art. 9 de la Ley de 13 de marzo de 1900(conforme a la redacción dada por la Ley de 8 de enero de 1907): "No se permitirá el trabajo a las mujeres durante un plazo de cuatro a seis semanas posteriores al alumbramiento. En ningún caso será dicho plazo inferior a cuatro semanas; será de cinco ó seis si de una certificación facultativa resultase que la mujer no puede sin perjuicio de su salud, reanudar el trabajo.

El patrono reservará a la obrera durante ese tiempo su puesto en el mismo.

La mujer que haya entrado en el octavo mes de embarazo podrá solicitar el cese en el trabajo, que se le concederá si el informe facultativo fuese favorable, en cuyo caso tendrá derecho a que se le reserve el puesto que ocupa...". 
cambiar el contexto jurídico, social, económico y político, alcanzaría un grado mucho mayor de observancia. A pesar de su falta de aplicación resulta interesante su análisis porque constituyó una verdadera referencia para la elaboración de las normas posteriores sobre la materia. Prueba de ello es que existió una continuidad en la regulación posterior del descanso maternal, como queda plasmado en la redacción de los arts. 166 y 167 sobre suspensión por maternidad de la Ley de Contrato de Trabajo del $44^{25}$. Su redacción es prácticamente idéntica a la del artículo noveno de la Ley de 13 de marzo de 1900 en la versión modificada por el Real Decreto de 21 de noviembre de 1923.

Palomeque basa la continuidad de dicha regulación en el hecho de que "en los años cuarenta, en que se produce la promulgación de la Ley de Contrato de Trabajo, apenas ha cambiado en nuestro país la estructura productiva del trabajo femenino y el modelo ideológico que inspiró la regulación de 1900. En ambos casos se tomó como referencia el sistema económico industrial, en el que..., la familia tiene un papel abrumadoramente consuntivo y en escasa manera productivo y en el que las mujeres y niños tienen la consideración laboral de medias fuerzas; la persistencia de similares esquemas socioeconómicos respecto al trabajo de la mujer explica la continuidad histórica de su regulación jurídica. Sólo cuando las transformaciones económicas y tecnológicas modifican el "status profesional" de la mujer, lo que en nuestro país empieza a acontecer a partir de 1960, en que se hace patente la contraposición entre los modelos ideológicos de "mujer para el hogar" y "mujer con participación social" puede hablarse de desfase normativo en relación con el sustrato socio-económico..." 26.

La configuración jurídica de la licencia por maternidad diseñada por las normas de las primeras décadas de 1900 permanecerá en lo esencial hasta nuestros días. El legislador de 1900 utilizó el mecanismo suspensivo con la

25 Ley de Contrato de Trabajo de 1944:

Art. 166: "Cualquiera que sea el contrato suscrito, toda mujer que haya entrado en el octavo mes de embarazo tendrá derecho a abandonar el trabajo, siempre que presente certificación médica en que haga constar que el alumbramiento se producirá aproximadamente en el término de seis semanas, y no se reiterará a su ocupación hasta que transcurra igual tiempo posterior al parto".

Art. 167: “En cualquiera de ambas circunstancias señaladas (embarazo, parto) en el artículo anterior, el patrono reservará a la obrera u operaria su puesto en el trabajo durante el tiempo que este obligada o autorizada a dejarle...".

C. Palomeque López (1975-76), pág. 271. 
intención de proteger la continuidad de la relación laboral cuando la trabajadora disfrutase del descanso por maternidad. Desde la promulgación de esta normativa al menos en el plano formal las ausencias de la mujer con motivo del alumbramiento ya no resolverían el contrato de trabajo.

El artículo noveno de la ley de 13 de marzo de 1900 (redactado de conformidad con la Ley de 8 de enero de 1907) delimitó por primera vez los rasgos esenciales caracterizadores de la figura suspensiva: inactividad laboral temporal, ausencia de remuneración y reserva de puesto de trabajo.

El lapso de tiempo de inactividad por causa del alumbramiento fue ampliándose en las sucesivas redacciones de la norma, distribuyéndose desde la primitiva redacción de 1900 en los siguientes períodos: uno, voluntario para la trabajadora, anterior al alumbramiento; otro obligatorio para la trabajadora y empresario, posterior al alumbramiento. Se contemplaba además la posibilidad de prorroga del período de inactividad cuando por motivos de salud apreciados por un facultativo la trabajadora no pudiera reincorporarse después de finalizado el descanso obligatorio.

Contrariamente a lo establecido en la norma, sería irremediable que en la mayoría de las situaciones la obrera trabajase también después del alumbramiento. Aznar señala en este sentido: "a la mujer, antes y después del parto, se le concedían derechos que no podía hacer efectivos y se le imponían deberes que no podía cumplir sino "a costa de su pan" y de la seguridad de su colocación en la empresa para la que trabajaba, lo cual significaba hacerlos gravosos y odiosos. La Ley que quería proteger a la mujer despertaba en ella un interés irresistible por burlarla, por no aprovecharse de sus beneficios, a los que valoraba en menos que sus perjuicios" 27.

La norma establecía formalmente la reserva del puesto de trabajo durante todo el período de inactividad, ya fuera antes o después del parto. Sin embargo, en el plano material, este derecho como los anteriores, al descanso antes y después del parto, sólo serían realidad cuando el patrono cumpliese pacíficamente sus términos. No existieron verdaderas consecuencias jurídicas por su incumplimiento; la única prevista fue la sanción pecuniaria con multa de veinticinco a doscientas cincuenta pesetas conforme a lo establecido en el propio artículo 13 de la Ley de 13 de marzo de 1900. Las autoridades municipales fueron las encargadas de la imposición y cobro de las referidas multas cuando lo determinaron las J untas locales y provinciales de Reformas

27 S. Aznar Embid (1932), pág. 5. 
Sociales, su producto era ingresado en las Cajas de las J untas locales y era teóricamente destinado a mejorar la educación del obrero.

Existen enormes dificultades para delimitar quiénes pudieron formar parte del colectivo de trabajadoras protegidas por la normativa de las primeras décadas del siglo XX. Señala Folguera al respecto que "las dificultades para conocer el trabajo femenino son enormes. Las fuentes estadísticas que nos permiten realizar un estudio de la evolución de la mano de obra durante el período de 1868 a 1930 son los censos que se realizan de forma regular todos los años, aunque la falta de homogeneidad en los mismos conduce a confusión. Las principales trabas que encontramos son: la confusión a la hora de integrar en la población activa a las mujeres debido a la situación familiar, lo que impide en la mayoría de los casos contabilizarlas como activas; la ocultación del trabajo a domicilio que emplea a una parte significativa de la mano de obra, y, por último, la no-declaración de la actividad cuando se realiza de forma parcial, dando lugar a una elevada cantidad de trabajo clandestino"28.

La delimitación que realizaremos de las trabajadoras incluidas y excluidas en el ámbito no pasa de ser una mera aproximación, basada en las escasas y ambiguas menciones acerca de este colectivo plasmadas en las normas de la época y también en la literatura científica sobre la materia tanto contemporánea como actual ${ }^{29}$. La normativa protege casi exclusivamente a las trabajadoras manuales de la industria (establecimientos fabriles y mercantiles) que representaban un colectivo bastante numeroso, mas de trescientas cincuenta mil mujeres en $1930^{30}$. El colectivo desprotegido fue aún más numeroso e igualmente desfavorecido, el grueso lo integraban:

a) las trabajadoras de la industria a domicilio;

b) las del servicio doméstico, aproximadamente doscientas ochenta mil mujeres en $1900^{31}$;

c) las trabajadoras agrícolas, casi doscientas sesenta y tres mil en $1930^{32}$.

28 P. Folguera Crespo (1997,b), pág. 477.

29 M. NASH (1983), pág. 50.

30 A. Schubert (1991), pág. 64.

31 R. Quesada Segura (1991), pág. 31.

32 M. Tuñón dE LARA (1972), pág. 371 y ss. 


\section{La escasa eficacia alcanzada por la normativa protectora de la materni- dad de las primeras décadas de $\mathbf{1 9 0 0}$}

Aun cuando hubo voluntad política de hacer cumplir esta ley y por ello alcanzó una mayor observancia que normas anteriores (por ejemplo, la Ley Benot...), esta norma, como todas sus coetáneas, fue incumplida sistemáticamente por los patronos, que sostuvieron una explicable resistencia frente a ella por ser restrictiva de sus privilegios ${ }^{33}$.

La organización encargada de vigilar y exigir su cumplimiento, compuesta fundamentalmente por las J untas locales y provinciales de Reformas Sociales y la Inspección de Trabajo, no desarrolló una labor muy eficaz en este terreno. Existió también una red de informadores de posibles infracciones compuesta por las asociaciones obreras, resultante de la declaración como públicas de las reclamaciones y denuncias por incumplimiento de la legislación laboral ${ }^{34}$.

El establecimiento de inspectores de trabajo por la geografía española fue muy lento debido a la escasez de recursos materiales y supuso la progresiva pérdida de las funciones de inspección de las J untas en aquellas localidades en que hubiera un inspector. Por ello, las J untas que hasta 1906 habían tenido el monopolio inspector negaron en un principio el carácter oficial de los inspectores y tuvieron una escasa colaboración con la Inspección de Trabajo. En numerosas ocasiones mantuvieron la postura de no dar traslado de las actas levantadas por los inspectores a las autoridades-alcaldes y gobernadores civiles- para la imposición de sanciones, o retrasaron indefinidamente la aplicación de las sanciones propuestas por aquellos. A la actitud de oposición mantenida por las Juntas cabe añadir la pasividad, cuando no la tolerancia y complicidad, que sostuvieron las autoridades -alcaldes y gobernadores civiles- encargados de sancionar las infracciones constatadas por los inspectores de trabajo ${ }^{35}$. Y, sobre todo, las dificultades presupuestarias que determinaron que la estructura administrativa de la Inspección tuviera por entonces escasos recursos materiales; un año después de su creación en 1907 tan sólo contaba con seis inspectores regionales ${ }^{36}$.

33 A. Martín Valverde et al. (1987), págs. 50 y 51.

34 Para todas estas cuestiones, más ampliamente, A. Martín Valverde, et al. (1987), pág. 56 y ss.

35 F. Pérez-Espinosa Sánchez (1977), págs. 62 y 63.

36 De la escasez de inspectores con que contó la Inspección en un primer momento da testimonio J osé González de CASTro (1914), pág. 55. 
Tampoco existió una jurisdicción específica adecuada a las necesidades de los justiciables sociales; D. Segismundo Moret anunciaba en la circular de 21 de junio de 1902 la reforma del "enjuiciamiento civil" con el fin de dotar de "rapidez", "baratura" y "carácter ejecutivo" a las cuestiones contenciosas laborales. Hubo que esperar a que el 19 de mayo de 1908 se dictase la Ley de Tribunales Industriales reformada el 22 de julio de 1912, cuyos efectos tardaron en ser sensibles ${ }^{37}$.

Respecto a los mecanismos para exigir su cumplimiento previstos en el reglamento de desarrollo de la Ley de 13 de marzo de 1900 tampoco fueron muy eficaces, dado que el legislador optó por castigar su incumplimiento con sanciones económicas frente a las penales. Dichas sanciones eran adoptadas por la autoridad local y sólo en teoría inmediatamente ejecutivas; se introdujo un nuevo instrumento para reforzar su cumplimiento: la denuncia pública de las infracciones empresariales ${ }^{38}$. El Real Decreto de 1 de marzo de 1906 que aprobó el Reglamento de la Inspección de Trabajo, si bien establecía un sistema de sanciones para castigar las infracciones a las leyes de trabajo, seguía recomendando "el sistema persuasivo", "instruyendo al patrono o jefe de la industria en sus deberes y obligaciones"39. Hubo una resistencia comprensible por parte del Estado, encarnado en esta élite de la que formaban parte las J untas de Reformas Sociales, la Inspección de Trabajo, Alcaldes y Gobernadores Civiles, a imponer coactivamente estas normas dado que recortaban privilegios de una buena parte de los sectores sociales que lo integraban ${ }^{40}$.

37 A. Martín Valverde, et al. (1987), pág. 50.

38 Las infracciones de la Ley de 13 de marzo de 1900 serán castigadas conforme al procedimiento establecido en los artículos 24 y 26 del capítulo 50 del reglamento de 13 de noviembre de 1900.

39 Resistencia estatal a la coacción a la que no eran ajenos los intereses empresariales, que llegaron a oponerse a la acción inspectora del Estado alegando que la visita de la inspección implicaba un delito de allanamiento de morada. Al paso de esta interpretación tuvo que salir la Real Orden de 22 de julio de 1907 que disponía la publicación de un informe del Instituto de Reformas Sociales, según el cual ni el centro de trabajo "es un verdadero domicilio "ni la entrada a él de un Inspector de trabajo constituye delito alguno".

40 Vid. M. Tuñón de LARA (1971), pág. 188. 


\section{Total ausencia de protección sanitaria y económica de la maternidad en la normativa de las primeras décadas de $\mathbf{1 9 0 0}$}

Las cifra relativa a la mortalidad general de las mujeres por motivo del parto en el período que va de 1906 a 1926 era de tres mil trescientas muertes de promedio anual. Nacían muertos también cerca de diecisiete mil niños cada año y morían más de noventa y siete mil antes de acabar el primer año de vida ${ }^{41}$. El problema se agravaba cuando se cuantificaba el número de muertes que correspondían a las clases obreras.

Íntimamente ligado con el problema sanitario se encontraba el pecuniario. En el momento del alumbramiento y en el período inmediatamente posterior las necesidades materiales de la trabajadora aumentaban y los medios disminuían por la pérdida de su salario durante el descanso. Aznar señalaba al respecto "si descansaba sin una compensación por los salarios perdidos por sus puertas entraba más que la salud, el hambre. Era preciso hallar la fórmula viable de que descansara y viviera, de que el hambre no fuera el siniestro y fatal acompañante de su descanso"42.

Fue muy escasa la iniciativa privada por parte de las propias obreras o de los empresarios y las organizaciones patronales para la creación de instituciones de seguro de maternidad que paliasen dicha situación. Fueron muy pocas las Mutualidades maternales organizadas por las obreras para defenderse de este riesgo; y pocas también las empresas que por estímulos de justicia, de caridad o de conveniencia establecieron para sus obreras Caja de Maternidad. La Inspección de Trabajo en sus memorias de la época refleja que en los centenares de visitas hechas a fábricas de las más diversas clases e importancia, tan sólo una en la provincia de Santander había puesto espontáneamente en funcionamiento un auxilio por maternidad. En la información pública abierta en la Conferencia de Seguros de Barcelona del año 1902 únicamente una organización patronal catalana hizo mención de una caja de maternidad organizada por ella ${ }^{43}$.

La ausencia de soluciones obedecería a causas económicas como la insuficiencia del salario de las obreras y la excesiva onerosidad de la implantación de estas instituciones cuando la carga económica pesaba

\footnotetext{
41 S. Aznar Embid (1932), pág. 5.

42 S. Aznar Embid (1932), pág. 4.

43 Vid. en extenso, F. Montero Aroca (1989), pág. 65 y ss. .
} 
íntegramente sobre las trabajadoras o sobre sus empresas. Y también a la falta de libertad de las mujeres para adquirir compromisos y disponer de su propio salario, unida a una carencia de cultura económica y de organización sindical generalizada ${ }^{44}$. En un primer momento el Estado se inhibió de intervenir al respecto; una ley que subvencionase y estimulase a las Mutualidades y Cajas Maternales hubiera contribuido a dar eficacia a la protección por maternidad reconocida en la Ley de 13 de marzo de 1900.

La protección económica y sanitaria imprescindible para dotar a la Ley de 13 de marzo de 1900 de realidad se incorporó a nuestro Derecho de la mano de una norma de carácter internacional, el Convenio núm. 3 de la Organización Internacional de Trabajo de fecha 29 de noviembre de 1919. El 29 de octubre de 1919 España participó en Washington en la primera conferencia internacional impulsada por la Sociedad de las Naciones para promover una legislación internacional del trabajo. Uno de los proyectos de Convenio allí discutidos fue el relativo al empleo de las mujeres antes y después del parto, gracias a la eficaz intervención de la representación española en su redacción el alcance de la norma se extendió a la mujer que trabajaba en establecimientos comerciales y no solamente a la de la industria ${ }^{45}$. España respaldó dicho Convenio y en consecuencia el Gobierno español quedó comprometido a someterlo al Parlamento; el 13 de julio de 1922 se promulgaba una ley ratificándolo y autorizando al Gobierno para aplicarlo ${ }^{46}$. Desde este momento el Gobierno tuvo luz verde para la creación de una Caja de Seguro

44 F. Montero Aroca (1989), pág. 66.

45 Vid. S. Aznar Embid (1932), pág. 3 y ss.

46 El artículo tres del Convenio núm. 3 de 29-11-1919 establecía:

“En todas las empresas industriales o comerciales, públicas o privadas, o en sus dependencias, con excepción de las empresas en que sólo estén empleados los miembros de una misma familia, la mujer:

a) no estará autorizada para trabajar durante un período de seis semanas después del parto;

b) tendrá derecho a abandonar el trabajo mediante la presentación de un certificado que declare que el parto sobrevendrá probablemente en un término de seis semanas;

c) recibirá durante el período en que permanezca ausente en virtud de los apartados a) y b), prestaciones para su manutención y la del hijo en buenas condiciones de higiene; dichas prestaciones cuyo importe exacto será fijado por la autoridad competente de cada país, serán satisfechas por el Tesoro público o se pagarán por un sistema de seguro. La mujer tendrá además derecho a la asistencia gratuita de un médico o de la comadrona

El error del médico o de la comadrona en el cálculo de la fecha del parto no podrá impedir 
Obligatorio de Maternidad, cuyo funcionamiento no se materializó hasta años más tarde y que con el transcurso del tiempo vendría a paliar y a resolver los problemas sanitarios y económicos de la madre trabajadora.

Las novedades más significativas incorporadas por el Convenio núm. 3 de la OIT fueron la percepción por la trabajadora de una prestación económica suficiente para su manutención y la de su hijo durante el período de ausencia por maternidad, junto a la asistencia sanitaria gratuita con motivo del alumbramiento dispensada por un médico o la comadrona ${ }^{47}$. Ahora bien, las novedades incorporadas quesignificaban mayores ventajas para las trabajadoras obligaron a modificar nuestro ordenamiento. En consonancia con ello el Real Decreto de 21 de agosto de 1923 reconoció el derecho de las mujeres asalariadas a la asistencia gratuita de un médico o de una comadrona ${ }^{48} ; \mathrm{y}$ al pago de una indemnización diaria suficiente para su manutención y la del niño en buenas condiciones de higiene. Para hacer efectivos estos derechos esta norma estableció, con carácter provisional hasta la implantación de la Caja del Seguro obligatorio de Maternidad, un régimen de subsidio tutelar de la obrera de cincuenta pesetas que satisfizo el Estado. Se encomendó al Instituto Nacional de previsión la administración y distribución del "Fondo Nacional de Maternidad" creado para atender a estos subsidios. El subsidio por maternidad costeaba la asistencia en el alumbramiento y para el sostenimiento de la madre y el hijo durante el reposo obligatorio después del parto. No podemos hablar de que esta norma implantase un seguro de Maternidad, pero sí preparó definitivamente el terreno y aportó una solución transitoria hasta la creación del mismo ${ }^{49}$.

quela mujer reciba las prestaciones a quetiene derecho desde la fecha del certificado médico hasta la fecha en que sobrevenga el parto".

47 La exposición de motivos del Real Decreto de 21 de Agosto de 1923 promulgado precisamente para dar aplicación a este Convenio así lo refleja: “...Sería pues una regresión de la legislación española ajustar ahora la protección de la maternidad a los límites profesionales que se señalan en el Recomendación adoptada en la sesión tercera de la Conferencia Internacional de Trabajo celebrada en Ginebra en 1921, referente a la protección de las mujeres empleadas en la agricultura, antes y después del parto, así como lo dispuesto en el art. 405 de la Parte XIII del tratado de Versalles, según el cual, "en ningún caso se pedirá a ninguno de los Miembros, como consecuencia de una recomendación o proyecto de Convenio que disminuya la protección ya concedida por su legislación a los obreros de que se trata".

48 C. Simón Palmer (1985), pág. 271.

49 Vid. en extenso, C. González Posada (1929), pág. 1 y ss.; y también A. Perpiñá (1972), Sociología de la Seguridad Social, Madrid, ed. Confederación Española de Cajas de Ahorros, pág. 97. 
El seguro obligatorio de Maternidad, sólidamente preparado por el Instituto Nacional de Previsión a partir de la experiencia del subsidio de maternidad, se implantó definitivamente por Real Decreto Ley de 22 de marzo de 1929. Con él se acabó con la inconsecuencia de imponer un descanso con motivo del alumbramiento con la consiguiente pérdida del salario sin que existiese una indemnización que paliase los efectos de este menoscabo económico; también se dio cobertura sanitaria a la trabajadora y el recién nacido. Y de este manera se cumplió el compromiso internacional adquirido con la ratificación del Convenio núm. 3 de la OIT $^{50}$.

De esta forma se inauguraba y quedaba instaurado en nuestro ordenamiento hasta la actualidad un sistema dual de protección a la maternidad, a través de medidas de protección laboral y de protección social complementarias que discurren estrechamente interconectadas, pero que jurídicamente son diferentes y deben ser tratadas diferenciadamente.

\section{Bibliografía}

Alarcón Caracuel, M. R. (1975), "El derecho de asociación obrera en España (1839-1900)", Revista de Trabajo, Madrid.

Albarracín Teulón, A. (1973), "La profesión médica ante la sociedad española del siglo XIX", Asclepio, Vol. 25, Madrid.

Alonso Olea, M. (1970), “'La Revolución Industrial y la emergencia del Derecho del Trabajo", Revista Trabajo, n 32.

Aznar Embid, S. (1932), El seguro obligatorio de maternidad, Madrid, ed. Publicaciones del Instituto Nacional de Previsión.

Bernaldo de Quiros, C. (1969), "El Instituto de Reformas Sociales", Revista de Trabajo $n^{\circ} 25$.

Folguera Crespo, P. (1997,a), Historia de las mujeres en España, Madrid, ed. Síntesis.

- (1997,b), "¿Hubo una revolución liberal burgués para las mujeres?”, en AAVV: Historia de las mujeres en España, Madrid, ed. Síntesis.

Fusl, J .P. y Palafox, J . (1997), España: 1808-1996. El desafío de la modernidad, Madrid, ed. Espasa Calpe.

50 Vid. Exposición de Motivos del Real Decreto de 22 de marzo de 1929. 
García Oviedo, C. (1934), Tratado elemental de Derecho Social, Madrid, ed. Librería General de Victoriano Suárez.

González de CASTRo, J . (1914), El trabajo de la mujer en la industria, Madrid, ed. Instituto de Reformas Sociales.

González PosadA, C. (1929), Los seguros sociales, Madrid, ed. Librería General de Victoriano Suárez.

IglesiAs, Mạ. C. y EloRZA, A. (1969), “Comisión de Reformas Sociales: información oral y escrita sobre el estado y las necesidades de la clase obrera (1884-1889)", Revista Trabajo, no 25.

Iglesias, M.C. y EloRzA, A. (1969), "La fundación de la Comisión de Reformas Sociales", Revista Trabajo, n 25.

KeMP, T. (1974), La Revolución Industrial en la Europa del siglo XIX, Barcelona, ed. Fontanella.

Lacomba, J. A. et al. (1976), Historia Social de España S. XX, Madrid, ed. Guadiana de Publicaciones.

López PenA, J . (1969), "Los orígenes del intervencionismo laboral en España: El Instituto de Reformas Sociales", Revista de Trabajo, n 25.

Martín Valverde, A. et al.(1987), La legislación social en la Historia de España (de la Revolución Liberal a 1936), Madrid, ed. Congreso de los Diputados.

Martínez Ródenas, M. (1912), El seguro maternal, Madrid, Publicaciones INP.

Molero Manglano, C. (1986), Fundamentos de las relaciones laborales colectivas, Madrid, ed. Reus.

Montalvo Correa, J . (1975), Fundamentos de Derecho del Trabajo, Madrid, ed. Civitas.

Montero Aroca, F. (1989), Orígenes y antecedentes de la previsión social, Madrid, ed. Ministerio de Trabajo y Seguridad Social.

Montero García, F. (1983), El Primer catolicismo social y la "Rerum Novarum" en España (1889-1902), Madrid, ed. Consejo Superior de Investigaciones Científicas.

Montoya Melgar, A. (1992), Ideología y lenguaje en las leyes laborales de España, Madrid, ed. Civitas. 
NAdAL Oller, J. (1975), El fracaso de la Revolución Industrial en España (18141913), Barcelona, ed. Ariel.

NASH, M. (1983), Mujer, familia y trabajo en España, (1875-1936), Barcelona, ed. Anthropos.

OpIsso, A., Medicina Social, Barcelona, ed. Manuales Gallach, (s.f.).

Palacio Morena, J. I. (1988), La institucionalización de la reforma social en España (1883-1924), Madrid, ed. Centro de Publicaciones Ministerio Sanidad y Seguridad Social.

Palomeque López, C. (1975-1976), “Orígenes de la regulación del trabajo femenino en España: La Ley del 13 de marzo de 1900", Cuadernos de Derecho del Trabajo, no 1 y 2.

Pérez-Espinosa Sánchez, F. (1977), Las infracciones laborales y la inspección de trabajo, Madrid, ed. Montecorvo.

Quesada Segura, R. (1991), El contrato de servicio doméstico, Madrid, ed. La Ley.

Schubert, A. (1991), Historia social de España 1800-1990, Madrid, ed. Nerea.

Simón PALMER, M a. C. (1985) , "La maternidad en España: ciencia o superstición”, ed. Asclepio, no 37.

TuÑón DE LARA, M. (1971), Estudios sobre el siglo XX español, Madrid, ed. Siglo XXI de España.

TUÑón DE LARA, M. (1972), El movimiento obrero en la historia de España, Madrid, ed. Taurus.

VILLA, L. E. DE LA (1970), “Nacimiento del derecho obrero en España”, en Actas del Primer Simposio de la Historia de la Administración Española, Madrid.

- (1971), "La elaboración científica en el Derecho del trabajo", separata del Anuario de Ciencia Jurídica, no 1.

Villa, L. E. de la y Palomeque, C. (1977), Introducción a la Economía del Trabajo, Madrid, ed. Debate.

Zulueta, C. de (1992), Cien años de educación de la mujer española, Madrid, ed. Castalia. 